\title{
Aplikasi Pencarian Surfing Spot Terdekat Di Bali menggunakan Formula Haversine Berbasis Web
}

\section{The Nearest Surfing Spot Search Application in Bali uses the Web-based Haversine Formula}

\author{
Rifky Lana Rahardian', I Nyoman Oksadhu Vinaya ${ }^{2}$, I Wayan Ari Yoga Diatmika ${ }^{3}$ \\ 1,2,3 ITB Stikom Bali \\ e-mail: rifky@stikom-bali.ac.id ${ }^{1}$, oksa.vinaya@gmail.com², ariyoga2016@gmail.com
}

\begin{abstract}
Abstrak
Indonesia merupakan negara kepulauan dan termasuk dalam negara yang memiliki garis pantai terpanjang ke empat di dunia. Selancar telah menjadi aktivitas yang sangat populer di beberapa pantai dengan ombak yang mendukung. Bali merupakan salah satu destinasi pariwisata yang selain menonjolkan adat dan budaya, juga memiliki kekayaan alam yang berlimpah begitupun dengan destinasi pariwisata pantai yang dapat dijadikan sebagai tempat selancar Permasalahan yang timbul adalah Beberapa wisatawan memilih tempat selancar yang pernah didengar saja sehingga wisatawan tersebut terkadang harus menempuh jarak yang lebih jauh dari tempatnya berada. Penelitian ini mempunyai tujuan untuk memberikan informasi mengenai lokasi tempat selancar serta dukungan pencarian terdekat. Aplikasi menggunakan rumus Haversine berbasis web untuk mencari tempat selancar terdekat di Bali dapat digunakan sebagai solusi untuk menampilkan informasi dan lokasi tempat selancar. Peneliti mengembangkan sistem informasi ini menggunakan metode waterfall. Berdasarkan hasil pengujian kuesioner dengan 10 responden menyatakan cukup sebesar 3\%, baik sebesar 31\%, dan sangat baik sebesar $66 \%$, bahwa aplikasi ini dapat membantu dan mempermudah wisatawan dalam mencari tempat selancar terdekat.
\end{abstract}

Kata Kunci: Tempat Selancar, Metode Waterfall.

\begin{abstract}
Indonesia is an archipelago and is one of the countries with the fourth longest coastline in the world. Surfing has become a very popular activity on some beaches with supportive waves. Bali is one of the tourist destinations that in addition to highlighting customs and culture, it also has abundant natural wealth as well as coastal tourism destinations that can be used as surfing spots. which is further away from where it is. This study aims to provide information about the location of the surfing spots and the nearest search support. The application uses the web-based Haversine formula to find the nearest surfing spot in Bali which can be used as a solution to display information and location of surfing spots. Researchers developed this information system using the waterfall method. Based on the results of questionnaire testing with 10 respondents, it is enough for $3 \%$, both $31 \%$, and very good at $66 \%$, that this application can help and make it easier for tourists to find the nearest surfing spot.
\end{abstract}

Keywords: Surfing Spot, Waterfall Method.

\section{Pendahuluan}

Indonesia merupakan negara kepulauan dan termasuk dalam negara yang memiliki garis pantai terpanjang ke empat di dunia [1]. Selancar (bahasa Inggris : surfing) telah menjadi aktivitas yang sangat populer di beberapa pantai dengan ombak yang mendukung, permintaan akan jumlah pantai untuk berselancar meningkat seiring dengan bertambahnya keinginan partisipan dalam berpartisipasi pada olahraga ini. Bertambahnya minat pada olahraga ini mengakibatkan banyak pantai yang awalnya tidak dikenal menjadi dikenal banyak orang dan mulai memperlihatkan eksistensinya di dunia pariwisata.

Bali merupakan salah satu destinasi pariwisata yang selain menonjolkan adat dan budaya, juga memiliki kekayaan alam yang berlimpah begitupun dengan destinasi pariwisata pantai yang dapat dijadikan sebagai surfing spot karena pantai-pantai tersebut dikenal tidak hanya memiliki pemandangan dan suasana yang indah tetapi juga memiliki ombak yang disukai banyak peselancar. Bagi wisatawan asing, pantaipantai yang ada di Bali memiliki ombak-ombak yang terkenal sebagai lokasi surfing untuk berselancar seperti di pantai Kuta, Uluwatu, Dreamland, dan pantai lainnya. Bagi mereka yang suka dengan hal-hal 
yang menantang yang memacu adrenalin seperti menyelam, rafting, treking dan lainnya semua juga bisa dilakukan di Bali [2].

Wilayah Bali Selatan yang memiliki pesisir pantai yang indah menyimpan banyak potensi objek wisata pantai yang masih tersembunyi dari wisatawan maupun masyarakat luas [3]. Beberapa wisatawan memilih surfing spot yang pernah didengar saja sehingga wisatawan tersebut terkadang harus menempuh jarak yang lebih jauh dari tempatnya berada.

Menurut Yulianto (2018) dalam penelitian yang berjudul "Penerapan Formula Haversine Pada Sistem Informasi Geografis Pencarian Jarak Terdekat Lokasi Lapangan Futsal”, dengan menerapkan formula Haversine pada SIG (sistem informasi geografis), user dapat melakukan perhitungan tentang seberapa jarak kita terhadap suatu objek kemudian dengan Direction Service dari Google, user juga dapat mengetahui jalur mana yang bisa tempuh untuk mencapai lokasi tersebut. Formula Haversine menghitung bahwa bumi bukanlah bidang datar, melainkan bidang dengan kelengkungan tertentu sehingga rumus Haversine adalah menghitung jarak antara dua titik di bumi berdasarkan panjang garis lurus antara dua titik, tanpa mengabaikan kelengkungan bumi.[4]

Berdasarkan hal tersebut maka perlu disediakan sebuah sistem yang memberikan informasi mengenai lokasi tempat selancar (surfing spot) serta dukungan pencarian terdekat. "Aplikasi Pencarian Terdekat Surfing Spot Di Bali mengunakan Formula Haversine Berbasis Web" dapat menjadi solusi dalam menampilkan informasi dan lokasi surfing spot kepada user khususnya wisatawan yang ingin berselancar di Bali.

Adapun teori dan literatur yang berkaitan dengan penelitian penulis sebagai berikut:

1. Sistem Informasi Geografis (SIG)

Menurut Raper J., Green H.[5], Sistem informasi geografis adalah sistem informasi komputer yang umumnya terintegrasi dengan lingkungan sistem komputer lain secara fungsional dan berjaringan. Sistem informasi geografis telah dirancang dengan menggunakan data yang berisi informasi spasial yang berkaitan dengan kondisi yang berlaku di bumi.

\section{Google Maps API}

Google Maps API adalah API yang paling populer di internet. Beberapa tujuan dari penggunaan Google Maps API adalah untuk melihat lokasi, mencari alamat, mendapatkan petunjuk mengemudi dan lain sebagainya [6]. Google Maps API adalah suatu library yang berbentuk JavaScript. Kita dapat menambahkan fitur Google Maps dalam web yang telah buat dengan Google Maps API [7].

\section{Sistem Koordinat}

Sistem koordinat digunakan untuk menampilkan suatu titik di permukaan bumi dari bujur dan lintang. Bujur adalah garis vertikal yang mengukur sudut antara suatu titik dengan titik nol bumi yaitu Greenwich yang merupakan garis bujur $0^{\circ}$ atau $360^{\circ}$ di permukaan bumi yaitu Greenwich. Sedangkan latitude adalah garis horizontal yang mengukur sudut antara suatu titik di permukaan bumi dan ekuator [8].

\section{Formula Haversine}

Formula Haversine merupakan sebuah formula (rumus) yang lumrah digunakan dalam sistem pemetaan. Penggunaan formula haversine digunakan dalam menentukan rentang jarak terpendek/terdekat di antara dua titik di bumi, bisa diumpakan pada suatu bola atau objek yang diambil dari garis bujur (longtitude) dan garis lintang (latitude) tanpa mengabaikan kelengkungan yang dimiliki objek. Formula ini ditemukan pertama kali pada tahun 1805 oleh Josef de Mendoza.Beliau pertama menggunakan formula ini di tahun 1801, sedangkan istilah "Haversine" diciptakan dan diperkenalkan oleh Profesor James Inman di tahun 1835[4].

Penggunaan formula haversine pada sistem navigasi, bertujuan untuk menentukan rentang jarak pada lingkaran besar, antara dua titik pada permukaannya (dalam hal ini, bumi) dengan mengacu kepada garis bujur dengan garis lintang. Formula ini menjadi metode untuk mengetahui jarak dari 2 titik dengan pertimbangan bahwa bumi adalah "spherical earth" atau bulat atau sebuah bidang dengan lengkungan . Rumus ini mengabaikan faktor dimana bumi itu sedikit elips atau disebut "elipsodial faktor" yang dapat dikatakan akurat dalam pengabaian ketinggian pada bukit atau kedalaman suatu lembah diatas permukaan bumi[4]. Berikut penjabaran dari formula haversine :
$\Delta$ latitude
= latitude 2 - latitude 1
$\Delta$ longitude
$=$ longitude 2 - longitude 1
a
$=\sin 2\left(\frac{\Delta \text { latitude }}{2}\right)+\cos ($ latitude1 $) \cdot \cos ($ latitude 2$) \cdot \sin 2\left(\frac{\Delta \text { longitude }}{2}\right)$
C

$$
=2 \tan 2(\sqrt{\alpha}, \sqrt{ }(1-\alpha))
$$


d $\quad=$ R.C

Dengan ketentuan dimana :

$\mathrm{R}=$ Jari-jari bumi ( biasanya digunakan : $6.371 \mathrm{Km}$ )

$\Delta$ lat $\quad=$ Selisih antara latitude A dan latitude B

$\Delta$ long $\quad=$ Selisih antara longitude A dan longitude B

$\mathrm{C}=$ Perhitungan perpotongan sumbu

$\mathrm{d} \quad=$ jarak/rentang $(\mathrm{Km})$

$1^{\circ} \quad=0.0174532925$ Radian

\section{Metode Penelitian}

\section{Metode Pengumpulan Data}

Pada penelitian ini, metode pengumpulan data yang digunakan adalah dengan wawancara, observasi, studi litelatur dan studi dokumentasi. Metode ini diperlukan untuk mengumpulkan dan mengolah data yang didapat dari objek diharapkan penelitian ini berjalan dengan baik dan sistematis terdiri dari Kuesioner dan Studi Pustaka.

\section{Metode Pengembangan Sistem}

Pada metode sistem ini yaitu merujuk pada metode waterfall. Metode pengembangan sistem ini terdiri dari pengumpulan data, analisa kebutuhan, desain sistem, implementasi sistem, pengujian sistem hingga penulisan laporan [9]:. Untuk lebih jelasnya, berikut merupakan gambar metode pengembangan sistem model waterfall [10]:

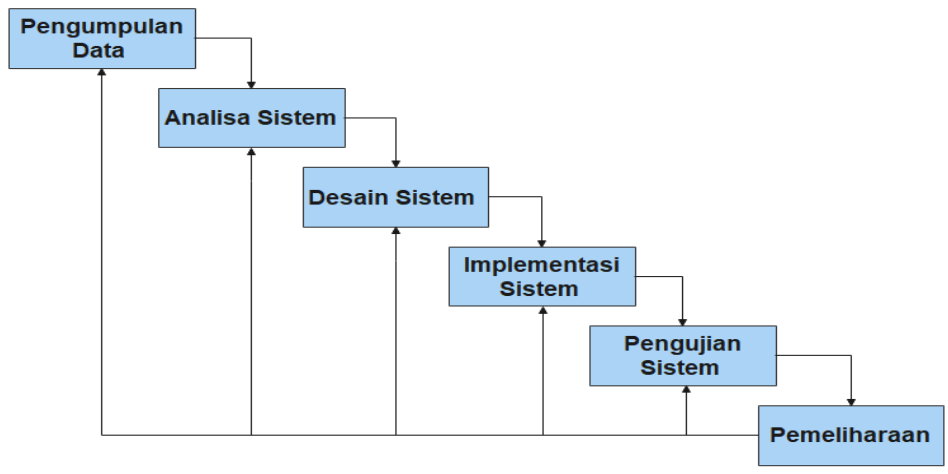

a. Analisa Kebutuhan

Gambar 1. Metode Pengembangan Sistem

Pada tahapan ini peneliti menganalisa kebutuhan yang diperlukan untuk pengguna. Pada tahapan analisa kebutuhan terdiri dari kebutuhan fungsional dan non fungsional adalah sebagai berikut:

1. Analisa kebutuhan fungsional merupakan kebutuhan yang berisi proses - proses apa saja yang nantinya harus disediakan oleh sistem.

2. Analisa kebutuhan non fungsional merupakan analisis yang berhubungan dengan kebutuhan pengguna sistem, kebutuhan perangkat keras dan perangkat lunak.

b. Desain Sistem

Pada tahapan ini, penulis melakukan tahapan desain sebuah program yang akan dibangun atau menggambarkan sistem yang akan berjalan agar mempermudah menjabarkan sistem sebelum pembutan code. Proses ini bertujuan untuk menjabarkan semua proses sistem yang akan dirancang. Proses perancangan sistem direpresentasikan dengan Flowchart, activity diagram, ERD, dan class diagram.

c. Implementasi Sistem

Pada tahapan ini, desain sistem yang dihasilkan dari tahapan sebelumnya akan diimplementasikan kedalam bentuk desain antarmuka Di mana hasil dari tahap ini adalah menghasilkan sistem informasi pencarian cepat surfing spot di bali menggunakan formula haversine berbasis web.

d. Pengujian Sistem 
Pada tahap ini penulis menguji sistem pada unit program untuk mengetahui apakah perangkat lunak yang dihasilkan sudah sesuai dengan desain dan masih terdapat kesalahan. Tahap pengujian sistem yang akan dilakukan dilakukan dengan dua metode yaitu penggunaan kuesioner dan metode pengujian black box. Setiap unit program akan diintegrasikan satu sama lain dan diuji sebagai sistem yang lengkap untuk memastikan bahwa sistem tersebut memenuhi persyaratan yang ada.

e. Pemeliharaan

Pada tahap ini prosedur yang telah diujicobakan dan dinyatakan memenuhi persyaratan kelulusan akan diimplementasikan langsung kepada masyarakat. Pada tahap pengembangan, admin akan melakukan pengecekan rutin untuk memastikan bahwa aplikasi berjalan dengan baik atau digunakan untuk mengupdate data.

\section{Hasil dan Pembahasan}

\section{Perancangan Data}

Aplikasi pencarian surfing spot ini terdekat menggunakan formula haversine dan dibangun dengan basis website bertujuan untuk memudahkan para user (pengguna) dalam mengakses layanan yang disediakan.

Dalam proses pencarian lokasi user, sistem akan memanfaatkan fitur dari Google Maps yaitu GeoLocation. Setelah mendapatkan titik dari user, maka dilanjutkan dengan mencari jarak antara titik koordinat user dengan titik surfing spot yang sudah diinput pada sistem menggunakan formula haversine. Setelah jarak antara kedua titik antara titik user dan masing-masing surfing spot ditemukan, maka dilakukan perbandingan untuk menentukan jarak atau selisih nilai terendah. Dari nilai tersebut, sistem akan memvisualisasikan dalam bentuk peta.

Visualisasi dari peta digital yang ditampilkan serta rute arah perjalanan dari titik user menuju titik surfing spot memanfaatkan API dari Google Maps. Sebagai contoh kasus, sistem akan mencari titik koordinat dari user, pada contoh kasus ini Monumen GWK (Garuda Wisnu Kencana) digunakan sebagai titik default. Setelah itu sistem akan melakukan perhitungan menggunakan formula haversine. Berikut dibawah ini merupakan contoh perhitungan dengan menggunakan formula haversine:

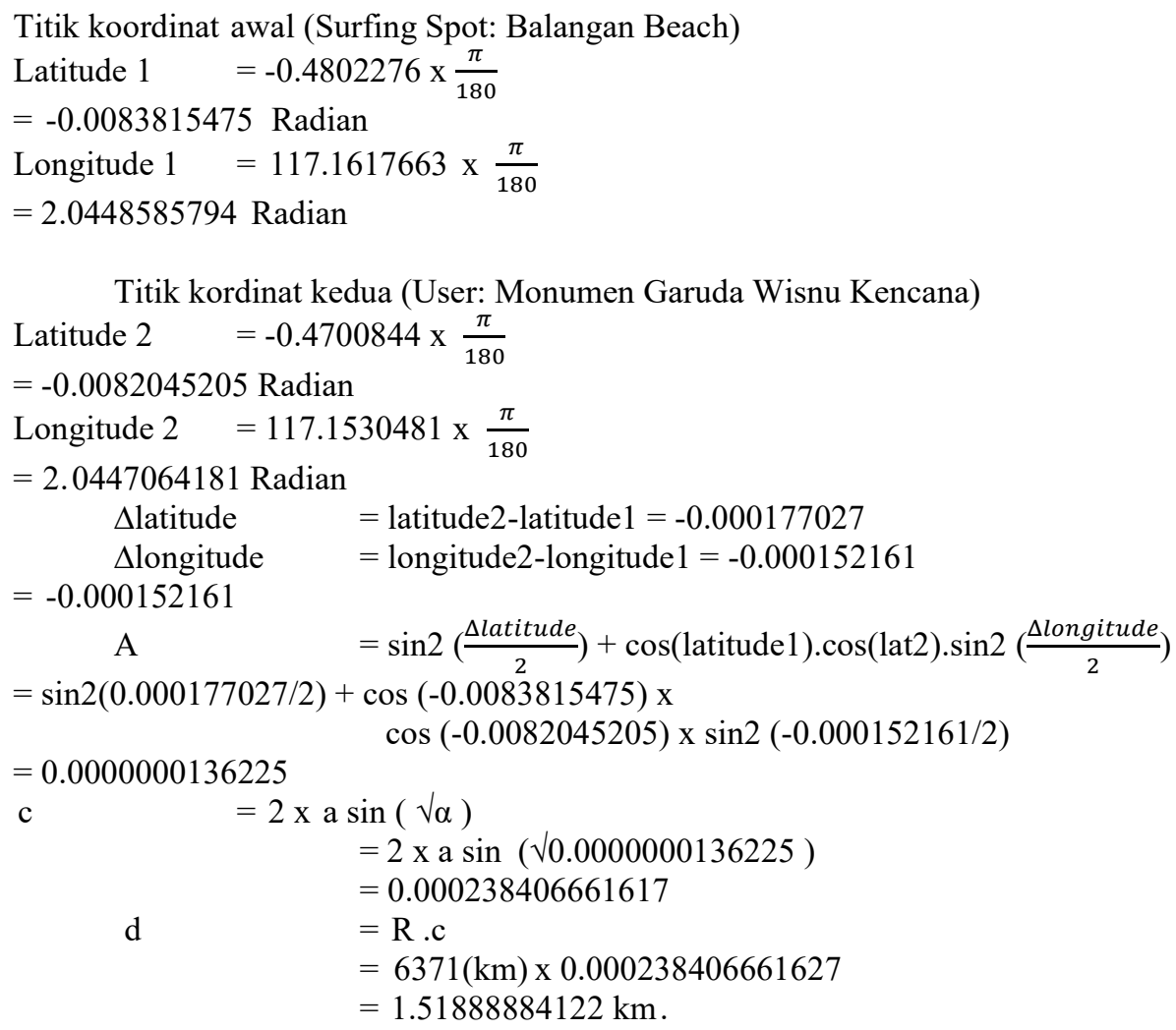

Berdasarkan pada contoh kasus diatas didapatkan jarak sebesar 1,5 km yang telah dihitung mengacu pada koordinat surfing spot Balangan Beach ke koordinat awal milik pengguna yaitu Monumen Garuda 
Wisnu Kencana. Setelah hasil tersebut ditemukan, proses pengurutan akan dilakukan sehingga didapatkan hasil dengan jarak terkecil yang dijadikan objek surfing spot yang paling dekat.

\section{Perancangan Proses}

Dalam activity diagram ini menunjukan alur proses pencarian terdekat surfing spot. Berikut activity diagram surfing spot terdekat :

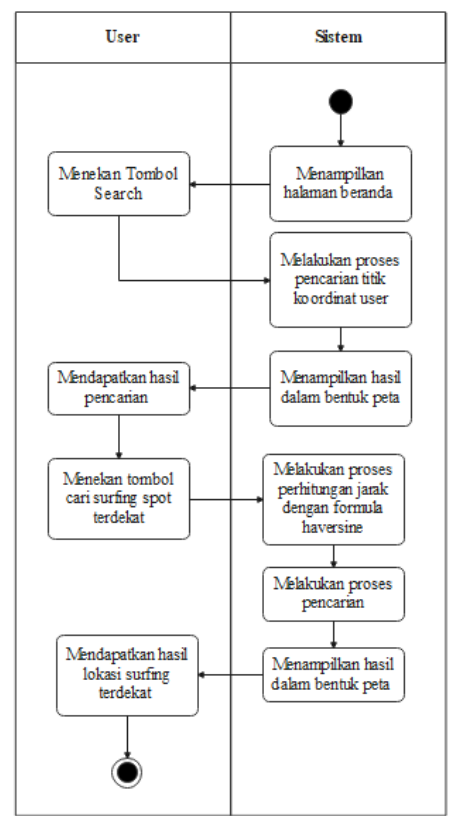

Gambar 2. Activity Diagram Surfing Spot

\section{Perancangan sistem}

Dalam gambar usecase diagram terdapat 2 aktor. Pertama, pegguna berperan sebagai aktor yang dapat melihat daftar surfing spot, mencari surfing spot terdekat, serta melihat detail surfng spot dalam sistem. Kedua, admin dapat mengelola sistem dengan melakukan login ke dalam halaman admin ,melihat daftar surfing spot, mencari surfing spot terdekat, menambahkan data surfing spot, menambah kategori surfing spot, melihat detail surfing spot, serta memperbarui data dan menghapus data.

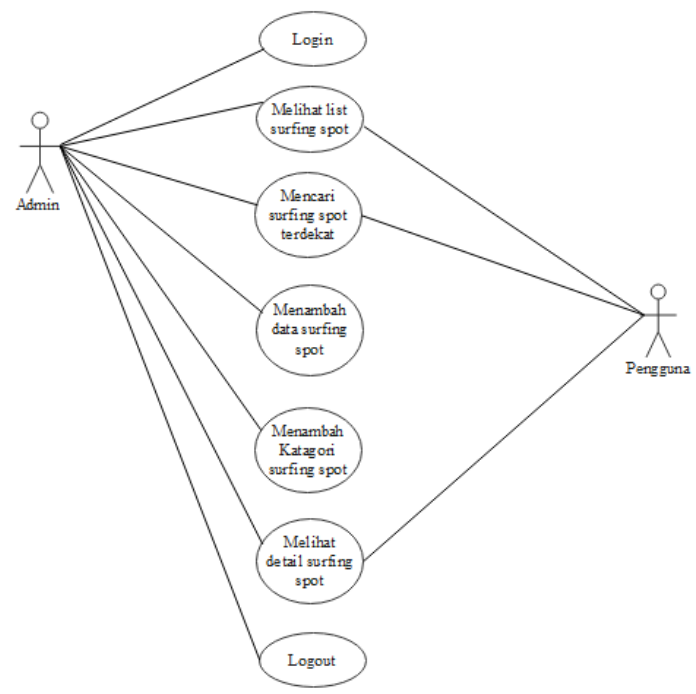

Gambar 3. Usecase Diagram Surfing Spot 


\section{Implementasi sistem}

a. Menu Pencarian Surfing Spot

Berikut adalah tampilan awal yaitu menu pencarian Surfing Spot, disini terdapat 3 menu diatas dan 1 menu dibawah. 3 menu diatas adalah Pencarian Surfing Spot untuk mencari Surfing Spot terdekat lalu ada List Surfing Spot untuk melihat data Surfing Spot yang pernah dicari oleh user dan ketiga ada Map untuk melihat lokasi user. Berikut ada tampilan dari Hasil pencarian setelah melakukan pencarian di menu pencarian Surfing Spot, disini terdapat 2 hasil pencarian dan letaknya. Dan juga ada tombol go untuk melihat detail dari surfing spot dan letaknya.

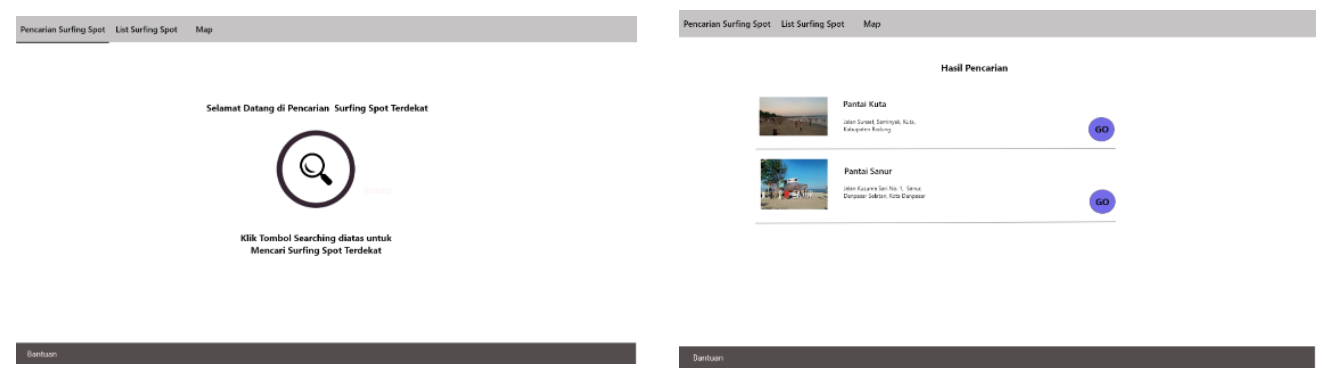

Gambar 4. Menu Pencarian Surfing Spot dan hasil pencarian

b. Detail Surfing Spot

Berikut adalah Tampilan Detail dan list Surfing Spot. Pada tab ini, detail dari Surfing Spot diperlihatkan kepada user berupa lokasi user dan rute untuk mencapai Surfing Spot

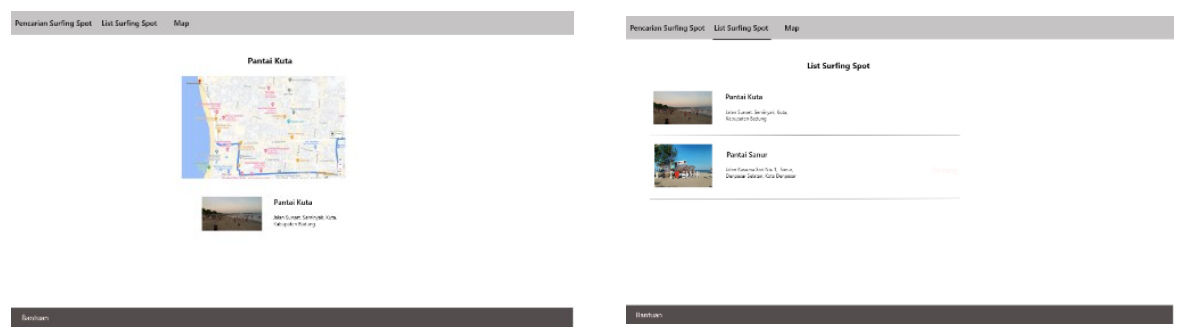

Gambar 5. Detail dan list Surfing Spot

c. Map

Berikut adalah tampilan dari Map yaitu tab yang berisi lokasi user dan Bantuan yang Berikut adalah tampilan Bantuan. Di dalam tab ini, user akan dibantu tentang penggunaan website Pencarian Surfing Spot Terdekat
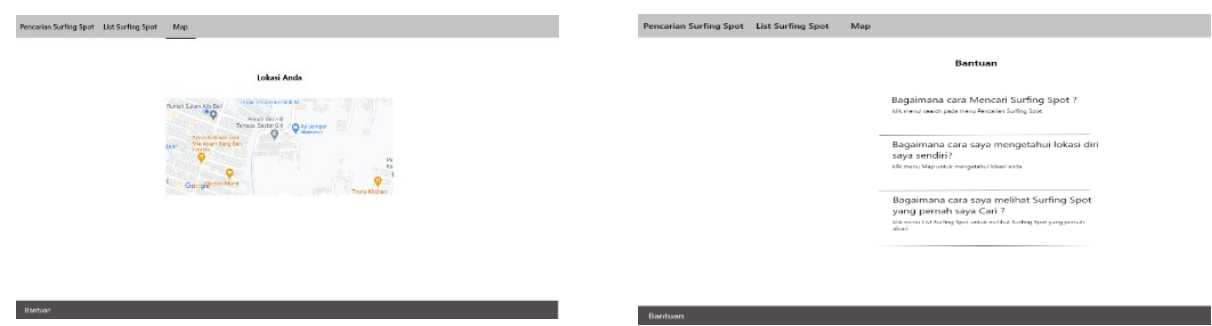

Gambar 8. Map dan Bantuan

\section{Kesimpulan}

Berdasarkan hasil analisis dan pengujian yang dilakukan terhadap Aplikasi Pencarian Terdekat Surfing Spot Di Bali Menggunakan Formula Haversine Berbasis Web, maka dapat disimpulkan sistem ini dapat mengetahui letak lokasi dan dapat memetakan lokasi surfing spot di Bali dengan menyertakan informasi terkait pantai tersebut dan system ini telah berhasil dijalankan sesuai fungsinya. Selain itu, Penerapan rumus Haversine mampu memberikan informasi jarak lokasi pengguna dari lokasi pantai lokasi surfing dan memberikan rekomendasi pantai terdekat, mencari hasil yang memiliki nilai paling rendah sebagai lokasi dengan yang jarak terdekat. 


\section{Daftar Pustaka}

[1] Aan nurdian Saputra, "UPT Perpustakaan ISI Yogyakarta," Perumusan Model Pengemb. Prod. Fotogr. Selancar Guna Perluasan Varian Prod. Fotogr. Freel., no. 8, pp. 13-26, 2012, [Online]. Available: http://www.jurnal.uii.ac.id/index.php/JEE/article/viewFile/4418/3906.

[2] I Made Suweta, "Kebudayaan Bali Dalam Konteks Pariwisata Budaya." C U L T O U R E : Culture Tourism and Religion, vol. 1, no. 1,pp. 1-14, 2020.

[3] I. W. W. Gautama, I. K. Gede, D. Putra, and I. M. Sukarsa, "Aplikasi Pemetaan Objek Wisata Pantai Bali Selatan Berbasis Android," Merpati, vol. 4, no. 1, pp. 43-51, 2016, doi: 10.24843/JIM.

[4] Y. Yulianto, R. Ramadiani, and A. H. Kridalaksana, "Penerapan Formula Haversine Pada Sistem Informasi Geografis Pencarian Jarak Terdekat Lokasi Lapangan Futsal," Inform. Mulawarman J. Ilm. Ilmu Komput., vol. 13, no. 1, p. 14, 2018, doi: 10.30872/jim.v13i1.1027.

[5] Widyatmoko, Nur, 2012, Pemanfaatan Geolocation dan Haversine Formulla dalam Perancangan Sistem Informasi Geografis (GIS) (Studi Kasus: Pariwisata Kabupaten Semarang), Repository Digital Library UKSW.

[6] Svennerberg, G. Beginning Google Maps API 3. New York: Springer, 2010.

[7] Asdani Kindarto, Asyik Berinternet dengan Beragam Layanan Google. Yogyakarta: Andi, 2008.

[8] R. Basaria, A. Setiawan, and E. Sediyono, "Penentuan luas wilayah kabupaten dan kota di provinsi sulawesi tengah menggunakan metode poligon dengan bantuan google earth Determination of regional areas of regency and city in central sulawesi province using polygon method by google earth," vol. 3, no. 1, p. 9, 2018.

[9] N. Chasanah, P. D. Abda'u, and M. N. Faiz, "Implementasi Metode Waterfall dalam Sistem Informasi Knowledge Management untuk Digital Marketing," Infotekmesin, vol. 12, no. 1, pp. 7180, 2021, doi: 10.35970/infotekmesin.v12i1.363

[10] Apriyanto Salwa, Fatimah Amalia, "Penerapan Model Waterfall Dalam Pembuatan Aplikasi Toko Kado," IJCIT (Indonesian Journal on Computer and Information Technology, vol. 3, no. 2, pp. 234-242, 2018. 